\title{
Pancreatic acellular matrix supports islet survival and function in a synthetic tubular device: In vitro and in vivo studies
}

\author{
E. DE CARLO ${ }^{1}$, S. BAIGUERA ${ }^{2}$, M.T.CONCONI ${ }^{2}$, S. VIGOLO ${ }^{2}$, C. GRANDI ${ }^{2}$, S. LORA ${ }^{3}$, \\ C. MARTINI ${ }^{1}$, P. MAFFEI ${ }^{1}$, G. TAMAGNO ${ }^{1}$, R. VETTOR ${ }^{1}$, N. SICOLO ${ }^{1}$ and P.P. PARNIGOTTO ${ }^{2}$ \\ ${ }^{1}$ Clinica Medica III, Hospital/University of Padova, Via Giustiniani 2, I-35128 Padova; ${ }^{2}$ Department of \\ Pharmaceutical Sciences, University of Padova, Via Marzolo 5, I-35128 Padova; ${ }^{3}$ Institute for the Organic Synthesis \\ and Photoreactivity, Italian National Research Council (CNR), Via Gobetti 101, I-40126 Bologna, Italy
}

Received July 31, 2009; Accepted September 29, 2009

DOI: 10.3892/ijmm_00000330

\begin{abstract}
Increasing pancreatic islet survival and function is a starting point for obtaining a valuable bioartificial pancreas for the treatment of type 1 diabetes. In this context, decellularized matrices, obtained after the removal of tissue cellular part, are known to support in vitro adhesion, growth, and function of several cell types. We demonstrate that a homologous acellular pancreatic matrix is a suitable scaffold for rat islet cultures maintaining their long-term viability and function. Islets adhered to the pancreatic matrix showed a constant glucose-induced insulin release during long-term in vitro incubation, while islets cultured without a matrix or on the liver matrix showed a progressive reduction. In order to obtain implantable devices, acellular matrix/islet cultures were entrapped into poly(vinyl alcohol) (PVA)/ poly(ethylene glycol) (PEG) tubes obtained by the freezing/thawing procedure. Under this condition, an in vitro constant insulin release was detected. The devices were then implanted into diabetic rats where reduced insulin requirement was noted suggesting insulin secretory activity of islets contained in the device. Indeed, immunofluorescence confirmed the presence of insulin- and glucagon-producing cells into the explanted devices. These data show that PVA/PEG semi-permeable membrane can obtain devices that restore, at least in part, insulin secretion.
\end{abstract}

\section{Introduction}

After transplantation, pancreatic islet survival depends on the efficiency of metabolic exchanges, the materials' biocompatibility, and prevention of the immune reaction against the graft. Despite the progress made regarding diabetic patients by

Correspondence to: Dr Eugenio De Carlo, Clinica Medica III, Hospital/University of Padova, Via Giustiniani 2, I-35128 Padova, Italy

E-mail: euge.decarlo@tiscali.it

Key words: acellular matrix, poly(vinyl alcohol), poly(ethylene glycol), islets, diabetes, insulin means of the Edmonton protocol (1), the poor availability of human organs for islet isolation and the chronic need for immunosuppressive drugs are two main limitations for its application in clinical practice $(2,3)$. Improving culture techniques and strategies to enhance the in vitro expansion rate of $\beta$-cells, extend in vitro islet cell maintenance and increase survival of grafted cells is essential. Several efforts have focused on the development of a bioartificial pancreas, in which transplanted pancreatic islets are integrated into synthetic, semipermeable membrane (4-9). However, so far, only a few approaches meet the technical or physiological requirements for application in human beings. The membrane used has to be permeable to small molecules, such as glucose and insulin, but fully impermeable to large molecules, such as antibodies and lymphocytes, avoiding the need for immunosuppressive therapy and allowing the use of non-human donor islets. Among biocompatible materials applied for the preparation of the bioartificial pancreas, poly(vinyl alcohol) (PVA), a watersoluble synthetic polymer forming thermoreversible, stable, highly elastic heterogeneous macroporous gels at low temperatures, was used $(10,11)$. PVA hydrogel is biocompatible and possesses low protein-binding tendency, high water content, and high porosity. PVA hydrogels are known to be applied in medicine and bio-technology. Lozinsky et al (12) reported that the addition of oligoethylene glycols (PEG) into the PVA solution gave rise to an increase in the gel's strength and thermostability. PEG is an uncharged, hydrophilic polymer, that is soluble in water as well as in many organic solvents. Due to its low toxicity and immunogenicity, PEG is highly suitable for biomedical applications (13), such as drug delivery. Lozinsky et al (12) reported that the addition of oligoethylene glycols, such as PEG-400 and PEG-1000, into the PVA solution gave rise to an increase in the gel strength and thermostability.

It has been demonstrated that the extracellular matrix (ECM) and its components affect the proliferation and the secretory function of many cultured cell types $(14,15)$ and, in particular, they support the in vitro long-term culture of pancreatic islets (16-19). Hammar et al (20) have shown that ECM protects pancreatic $\beta$-cells from apoptosis leading to improved cell survival. Moreover, studies on $\beta$-cells cultured on various crude matrices or on their purified extracts highlighted the 
importance of cell-ECM interactions for optimally regulated insulin secretion (17,21-26). Tissue engineering studies have also shown that scaffolds derived from decellularized matrices, obtained after the removal of the cellular component, support in vitro adhesion, growth, and function of several cell types (27-29) and act as a template for growth and tissue remodelling (30-35).

Based on these considerations, in this study we ascertained whether pancreas and/or liver acellular matrices support the pancreatic islet secretory function. Then after, in vitro and in vivo survival and function of islets cultured on acellular matrix and entrapped into PVA/PEG cryogel tubular devices was evaluated.

\section{Materials and methods}

Animals. All animal experimental procedures were carried out in accordance with the National Institute of Health (NIH) guidelines regulating laboratory animal care and specific Italian laws regarding animal experiments. Male Wistar rats (190-210 g) were provided by Charles River (Calco-Lecco, Italy) and received standard chow and water ad libitum before experiments.

Islet isolation. Pancreatic rat islets were isolated after collagenase digestion according to the Lacy and Kostianovski method (36) with minor modifications as already reported (37).

Acellular matrix preparation. Rat pancreas and liver acellular matrices (AMs) were prepared by the Meezan method (38), with minor modifications. Rats were anaesthetized with pentobarbital and sacrificed by decapitation. After laparotomy and papilla Vateri clamping, the hepatic duct was cannulated and the pancreas distended by injecting $15 \mathrm{ml}$ of distilled water. Then, the pancreas was removed and cleaned of lymph nodes and fat. Cryostatic $240-\mu \mathrm{m}$ slices of whole pancreas or liver were processed with distilled water for $1 \mathrm{~h}$ at $4^{\circ} \mathrm{C}, 4 \%$ sodium deoxycholate (Sigma, St. Louis, MO, USA) for $30 \mathrm{~min}$, and 2,000 kU deoxyribonuclease I (DNase-I) (Sigma) in $1 \mathrm{M}$ $\mathrm{NaCl}$ (Sigma) for $20 \mathrm{~min}$. The lack of cells or cell debris was confirmed histologically (haematoxylin-eosin staining), and AMs were stored in PBS at $4^{\circ} \mathrm{C}$ until use.

Acellular matrix-islet cultures. Pancreatic and liver AMs, prepared the day before cell seeding, were carefully washed twice with PBS and placed at the bottom of the wells of 24-well tissue culture plates. Batches of 50 freshly isolated islets were then handpicked and transferred into each well containing AMs or not. All cultures were kept at $37^{\circ} \mathrm{C}$ in a humidified atmosphere of $95 \%$ air $5 \% \mathrm{CO}_{2}$. Islets were cultured in RPMI-1640 medium (Gibco, Paisley, UK) containing $5.6 \mathrm{mM}$ glucose, $10 \%$ heat-inactivated foetal calf serum (FCS, Gibco), $100 \mathrm{IU} / \mathrm{ml}$ of penicillin and $100 \mu \mathrm{g} / \mathrm{ml}$ of streptomycin (Sigma). The culture medium was changed every 2-3 days. Weekly, after removal of culture medium, islets were washed twice with Krebs-Ringer-HEPES buffer (KRHB) containing 0.1\% BSA (Sigma) plus glucose $1.4 \mathrm{mM}$, and then treated for $2 \mathrm{~h}$ in KRHB with $0.1 \%$ BSA plus $22 \mathrm{mM}$ glucose (Sigma). At the end of the incubation period, the buffers were collected and stored at $-20^{\circ} \mathrm{C}$ until insulin assay.
Fresh RPMI-1640 medium was added and islets were kept in culture again. Glucose challenge was carried out at 7, 14, 21, 28,35 and 42 days of culture.

Polymer. Poly(vinyl alcohol) (PVA), $\left(\mathrm{CH}_{2} \mathrm{CHOH}\right)_{\mathrm{n}}$, (Aldrich, USA), molecular weight 124,000-186,000, 99+\% hydrolyzed and poly(ethylene glycol) (PEG-400) (Aldrich, USA), average $\mathrm{Mn}=380-420$ were used as received.

PVA/PEG tube preparation. The procedure is based on the property of PVA to form crystallites when cooled at a low temperature. Tubular PVA/PEG membranes were obtained by the freezing/thawing method. Aqueous PVA solution was obtained (polymer concentration $12 \mathrm{~g} / \mathrm{dl}$ ) by heating at $95^{\circ} \mathrm{C}$ until dissolution for 3-4 h with periodical shaking. PVA solution obtained was centrifuged to remove impurities. PEG 400 (in the ratio PEG/PVA 15/100) was then added to polymer solution in order to reinforce the matrix. PVA/PEG solution was poured into a 2-mm diameter glass tube in which a glass bar was concentrically inserted and fixed in order to obtain a tubular membrane with a uniform thickness of about $100 \mu \mathrm{m}$. Then, three freeze-thawing cycles of $30 \mathrm{~min}$ (cooling cycles at $-25^{\circ} \mathrm{C}$ and heating at room temperature) were carried out, in order to speed up the jellification process. After removal of the glass tube and bar, the tubular PVA/PEG had an external diameter of $2 \mathrm{~mm}$ and a thickness of $0.15 \mathrm{~mm}$. Finally, it was sterilized by Co-60 $\gamma$ ray irradiation ( $25 \mathrm{~Gy}$ ).

Pancreatic device preparation and in vitro studies. Based on previous in vitro findings, the pancreatic acellular matrix was chosen as a scaffold for islet cultures. Pancreatic islets (50/piece) were seeded on 5 acellular matrix round pieces (2-mm diameter) into 48-well plates and cultured under standard conditions. After 7 days, 5 islet-matrix complexes were inserted into the tubular PVA/PEG devices. The expected number of islets was 250 for each device, but the actual number was inestimable at microscope observation due to the three-dimensional structure of the device. The PVA/PEG tubes were sealed with PVA/PEG small plugs inserted into each end, externally fixed by surgical wire and incubated in vitro. Each experiment was carried out in triplicate and the 22-mmol/1 glucose challenge was performed weekly until the 63rd day of incubation. At the end of a 2-h incubation period, the buffer was collected and stored at $-20^{\circ} \mathrm{C}$ until insulin assay.

Pancreatic device implantation and evaluation of metabolic status. Rats were made diabetic with a single dose of streptozotocin (100 mg/kg intraperitoneally, Sigma) (SPZ). Blood glucose was measured daily by a portable glucometer (Glucocard Memory PC, Menarini Diagnostics, Florence, Italy) from blood obtained by tail snipping. Rats were used as recipients only when non-fasting glucose levels were $>22 \mathrm{mmol} / \mathrm{l}$, with evidence of glycosuria measured by urine strips (Aution Sticks 10 EA, Menarini Diagnostics). Diabetes was evident after $\sim 2$ days from streptozotocin injection.

In the first experimental series, after blood glucose measuring, SPZ diabetic rats were treated subcutaneously with insulin bis in die (Actraphane $30 / 70^{\circledR}$ at 8.00 and Ultratard ${ }^{\circledR}$ at 19.00, Novo Nordisk, Bagsvaerd, Denmark), in order to maintain glucose levels $<11 \mathrm{mmol} / \mathrm{l}$. Before administration, 
insulin was diluted 1:10 (v:v) with $\mathrm{NaCl} 154 \mathrm{mmol} / \mathrm{l}$ solution (Sigma). Seven days after SPZ administration, rats $(n=18)$ were anaesthetized with an intraperitoneal injection of ketamine $(35 \mathrm{mg} / \mathrm{kg}$, Ketalar, Parke Davis, Lainate-Milano, Italy) and xylazine $(5 \mathrm{mg} / \mathrm{kg}$, Rompun, Bayer, Leverkusen, Germany) and prepared by shaving their backs and making a 10-mm midline incision. Animals were randomly divided into three groups. In group $1(n=6)$, three PVA/PEG devices containing the pancreatic acellular matrix and islets were subcutaneously inserted, whereas groups $2(n=6)$ and $3(n=6)$ received matrix-PVA devices (without islets) and islets adherent to pancreatic acellular matrices, respectively. Then, the skin was sutured by surgical wire. Glucose levels were immediately measured from rat tail blood and subcutaneous insulin was administered in order to restore euglycaemia avoiding islet glucotoxicity. During the following days, glycaemic levels were measured twice a day (at 8.00 and at 19.00) and insulin treatment b.i.d. was continued. Every $24 \mathrm{~h}$, glycosuria and body weight were also monitored.

In the second experimental series, rats were not treated with insulin until the implantation. Seven days after SPZ, six diabetic rats were implanted with six devices each in group 1. Groups $2(n=6)$ and $3(n=6)$ received matrix-PVA/PEG devices (without islets) and islets adherent to pancreatic acellular matrices, respectively. Glucose levels were immediately measured with the glucometer from rat tail blood and subcutaneous insulin was administered at once and for the three days after as described above, in order to maintain the glycaemia near $11.0 \mathrm{mmol} / \mathrm{l}$, avoiding a marked acute glucotoxicity of islet inside the bioreactors. The days following the implantation, glycaemic levels were measured daily at 8.00. In all rats, insulin plasma levels were measured before SPZ, the day of implantation, weekly after implantation, and two days after the implant removal, by tail vein withdrawal. The 49th day after implantation devices were removed.

Insulin assay. Insulin was assayed by radioimmunoassay (RIA) using a commercial kit (Linco Research, St. Charles, MO) using rat insulin as the standard. Insulin release in the medium was expressed as pg ml-1 $120 \mathrm{~min}^{-1}$. Insulin plasma level was expressed as $\mathrm{ng} / \mathrm{ml}$.

Histological analysis. After the device removal, grafts were fixed in $10 \%$ neutral buffered formalin (Sigma) for $24 \mathrm{~h}$ and embedded in paraffin. Transversal sections $(5 \mu \mathrm{m})$ were stained by Aldehyde-Fuchsin method (39), to detect the secretion granules in B-cells. Briefly, after removal of paraffin, slides were treated with Lugol's iodine solution and iodine was removed with $5 \%$ aqueous sodium thiosulfate (Sigma). Slides were placed in $70 \%$ alcohol and stained in Aldeyde-Fucsin (Sigma) for $1 \mathrm{~h}$, dehydrated in absolute alcohol, and mounted in synthetic resin (Vector Laboratories, Peterborough, UK). Alternatively, samples were fixed for $20 \mathrm{~min}$ at room temperature in 4\% PFA (Sigma), then incubated with $\mathrm{NH}_{4} \mathrm{Cl}$ $50 \mathrm{mM}$ (Sigma) for $30 \mathrm{~min}$ and with $10 \%$ blocking serum (Gibco) in PBS for $30 \mathrm{~min}$ at room temperature. Samples were then incubated overnight at $4^{\circ} \mathrm{C}$ with monoclonal anti-insulin (1:50, Sigma) and anti-glucagon (1:3,000, Dako, Glostrup, Denmark), diluted in $1 \%$ saponin $0.1 \%$ (Sigma) and $1 \%$

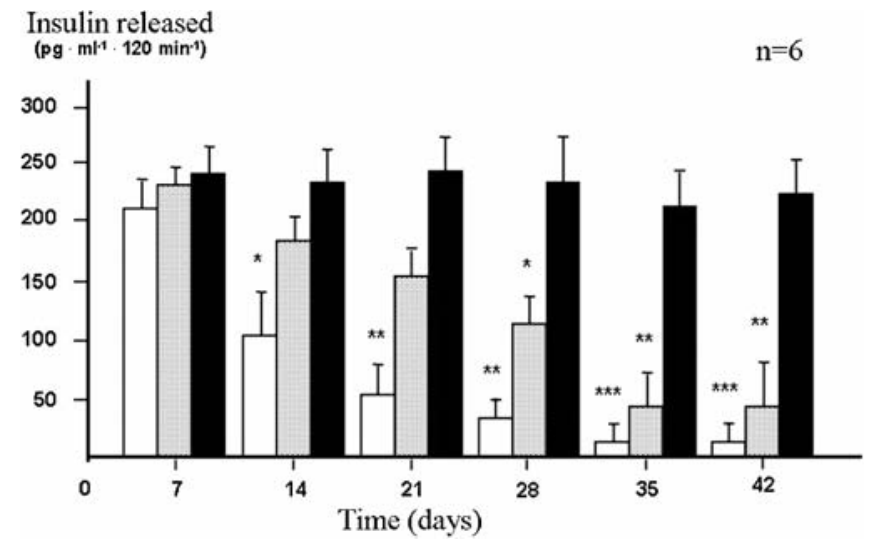

Figure 1. Glucose $(22 \mathrm{mmol} / \mathrm{l})$-induced acute insulin release from islets cultured on tissue culture treated dishes (grey bar), liver AM (white bar) and pancreatic AM (black bar). Each stimulation was carried out weekly starting from the 7 th day of incubation. The values are the mean $\pm \mathrm{SD}$ of $\mathrm{six}$ independent experiments. ${ }^{*} \mathrm{p}<0.05,{ }^{* *} \mathrm{p}<0.001 \mathrm{vs} .7$ th day release.

blocking serum in PBS. Secondary antibody specific for appropriate host species conjugated with Alexa Fluor 488 (1:500, Invitrogen, Milano, Italy) and 555 (1:3,000, Invitrogen) was used for fluorescence staining. Fluorescence images were obtained using a fluorescent microscope (Leica, Wetzlar, Germany).

Data analysis. Results were expressed as mean \pm SEM of three separate experiments. The least significant difference (LSD) test was performed for statistical analysis of culture data. Statistical analysis of in vivo exogenous insulin dose and of weekly insulin plasma levels was performed by one-way Analysis of variance followed by Student's t-test for unpaired data. Significant level was set at $p<0.05$. The StatSoft software (Tulsa, OK, USA) was used.

\section{Results}

Acute glucose challenge of matrix-islet cultures. Insulin release was measured at the end of $2 \mathrm{~h}$ incubation in medium containing $22 \mathrm{mmol} / \mathrm{l}$ glucose. The acute glucose challenge was carried out weekly, starting from the 7th day of culture (Fig. 1). Islets cultured on tissue culture-treated dishes showed a progressive reduction of insulin release, that became statistically different, with respect to the 7-day level, after 28 days $(98 \pm 19$ vs. $\left.219 \pm 13 \mathrm{pg} \cdot \mathrm{ml}^{-1} \cdot 120 \mathrm{~min}^{-1}, \mathrm{p}<0.05\right)$. Insulin release was nearly abolished after 35 days. Islets cultured on liver AM showed a significant $(\mathrm{p}<0.05$, after 14 days $)$, very significant $(\mathrm{p}<0.01$ after 21 and 28 days), and highly significant $(\mathrm{p}<0.001$ after 35 and 42 days) decreasing trend during the observation period, being nearly abolished after 28 days culture. The reduction observed was stronger than islets cultured in tissue culturetreated dishes. On the contrary, islets cultured on pancreatic AM still demonstrated their function of secreting insulin after 42 days incubation.

PVA/PEG tubes. As shown in Fig. 2, PVA/PEG tubular device had a asymmetric structure of a thin continuous homogeneous external surface with a trabecular, porous internal structure. 


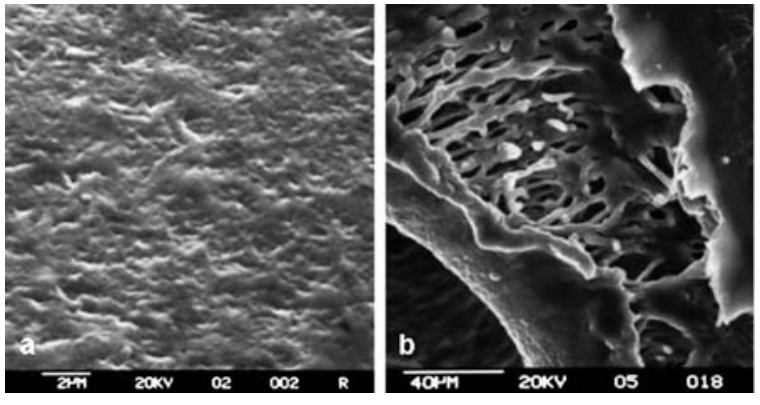

Figure 2. Micrographs of scanning electron microscopy of the PVA device, showing (a) external and (b) internal surface.

In vitro evaluation of the pancreatic device functionality. As reported, pancreatic AM resulted to be favourable for long-term islet survival. We decided to further evaluate only this matrix in the pancreatic device. The release of glucose-induced insulin was evaluated either from islets adherent to pancreatic AM only and from islets adherent to pancreatic AM and cultured in the PVA/PEG tubular semi-permeable device. The insulin release was measured at the end of $2 \mathrm{~h}$ incubation in medium containing $22 \mathrm{mmol} / \mathrm{l}$ glucose and was carried out weekly during 63 days culture. As Fig. 3 shows, insulin release remained constant during all the observation period in both experimental conditions, with pancreatic AM islets cultured in

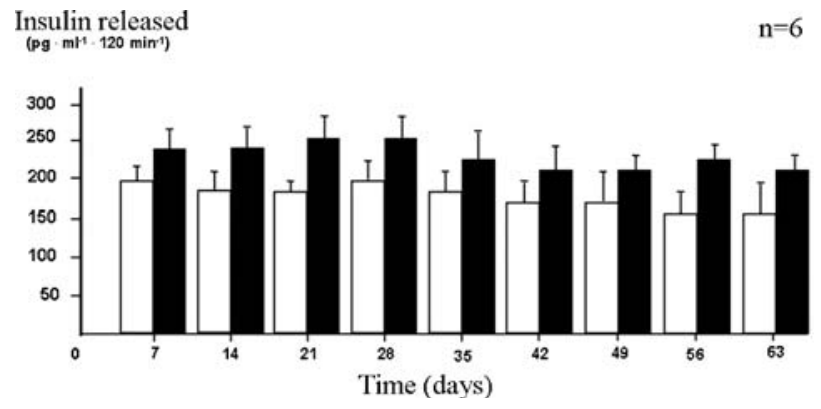

Figure 3. Glucose (22 mmol/l)-induced acute insulin release from islets cultured on pancreatic AM (closed bar) and from islets adherent to pancreatic AM and sealed in the PVA tubular semi-permeable device (open bar). Each stimulation was carried out weekly, starting from the 7th day of incubation. The values are the mean $\pm \mathrm{SD}$ of six independent experiments. No statistically significant difference was observed.

the PVA/PEG device resulting in a slight, but not statistically significant, reduction with respect to islet-pancreatic AM complex without PVA/PEG.

In vivo evaluation of pancreatic devices. In order to maintain euglycaemia, SPZ diabetic rats, either control and implanted, were treated with insulin bis in die (at 8.00 and at 19.00). As shown in Fig. 4, a reduction of daily exogenous insulin requirement was observed in implanted rats, with respect to the
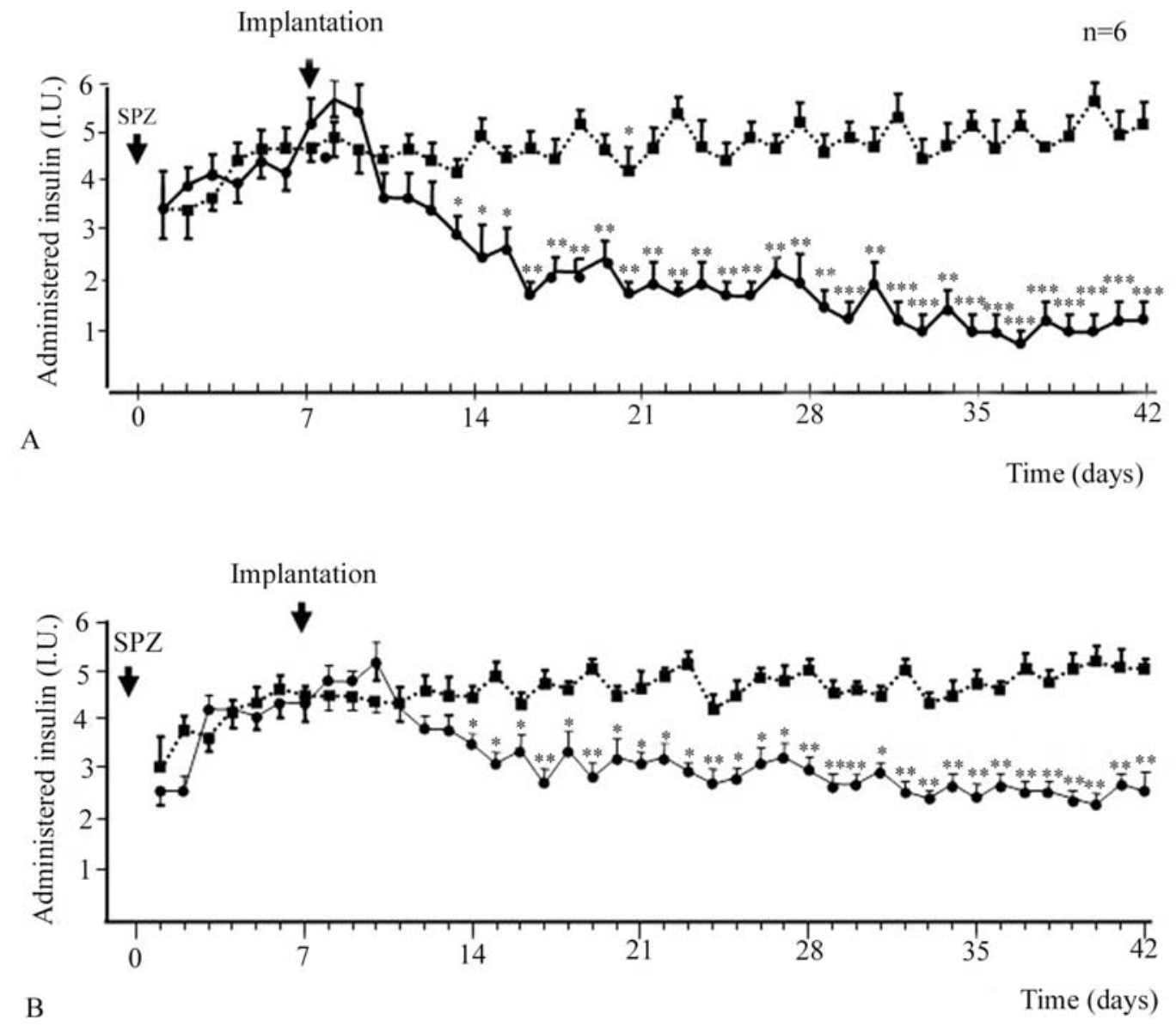

Figure 4. Insulin administered dose in order to normalize glucose levels of SPZ diabetic rats implanted with three bioreactors ( $\bullet-\bullet)$ and of control SPZ diabetic rats $(\cdots \cdots)$. Time course of $(\mathrm{A})$ morning and (B) evening administrations in the same rats. The values are expressed as mean \pm SD. ${ }^{*} \mathrm{p}<0.05,{ }^{* *} \mathrm{p}<0.01$, ${ }^{* * *} \mathrm{p}<0.001$ vs. control rats. 


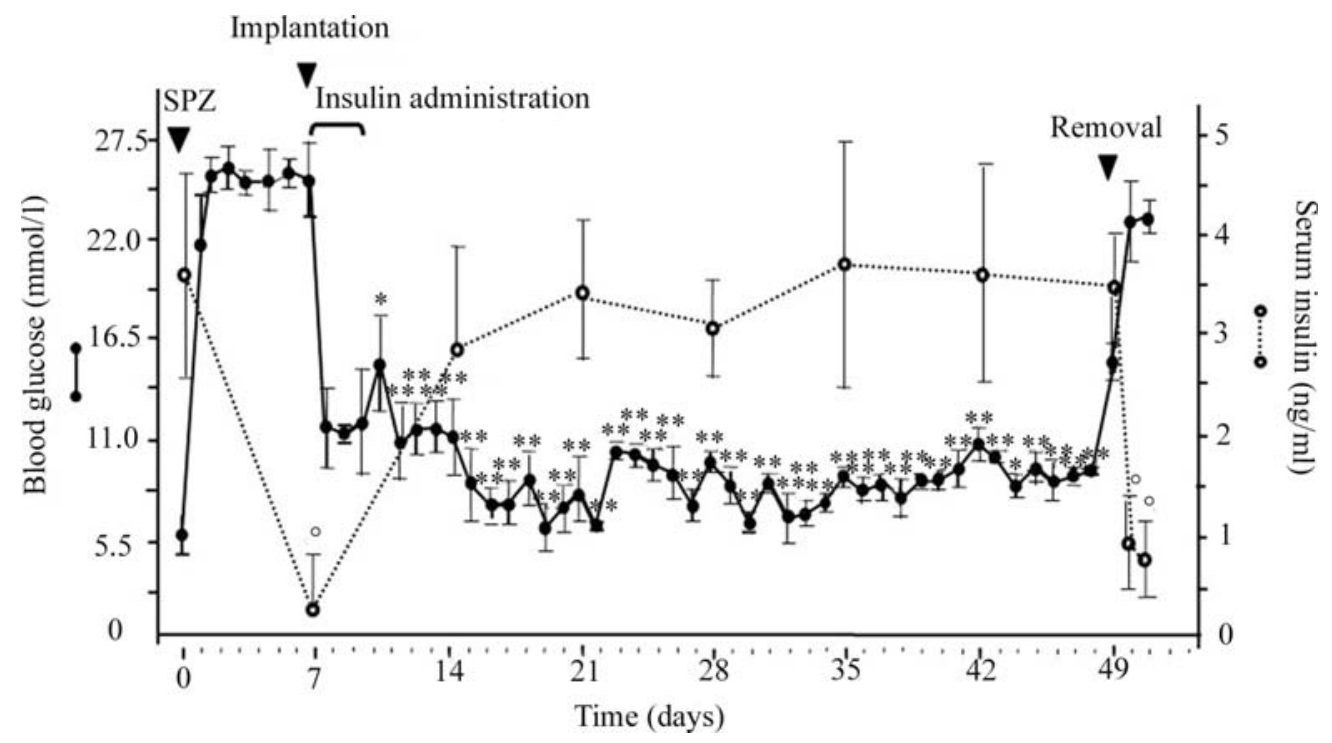

Figure 5. Time course of daily glucose $(\bullet-\bullet)$ and of weekly plasma insulin $\left(\cdots_{\circ}\right)$ levels in diabetic rats before and after the implantation and after the removal of 6 bioreactors. The values are expressed as mean $\pm \mathrm{SD}$. ${ }^{*} \mathrm{p}<0.05$ and ${ }^{* *} \mathrm{p}<0.01$ vs. implantation day, ${ }^{\circ} \mathrm{p}<0.05$ vs. SPZ day.

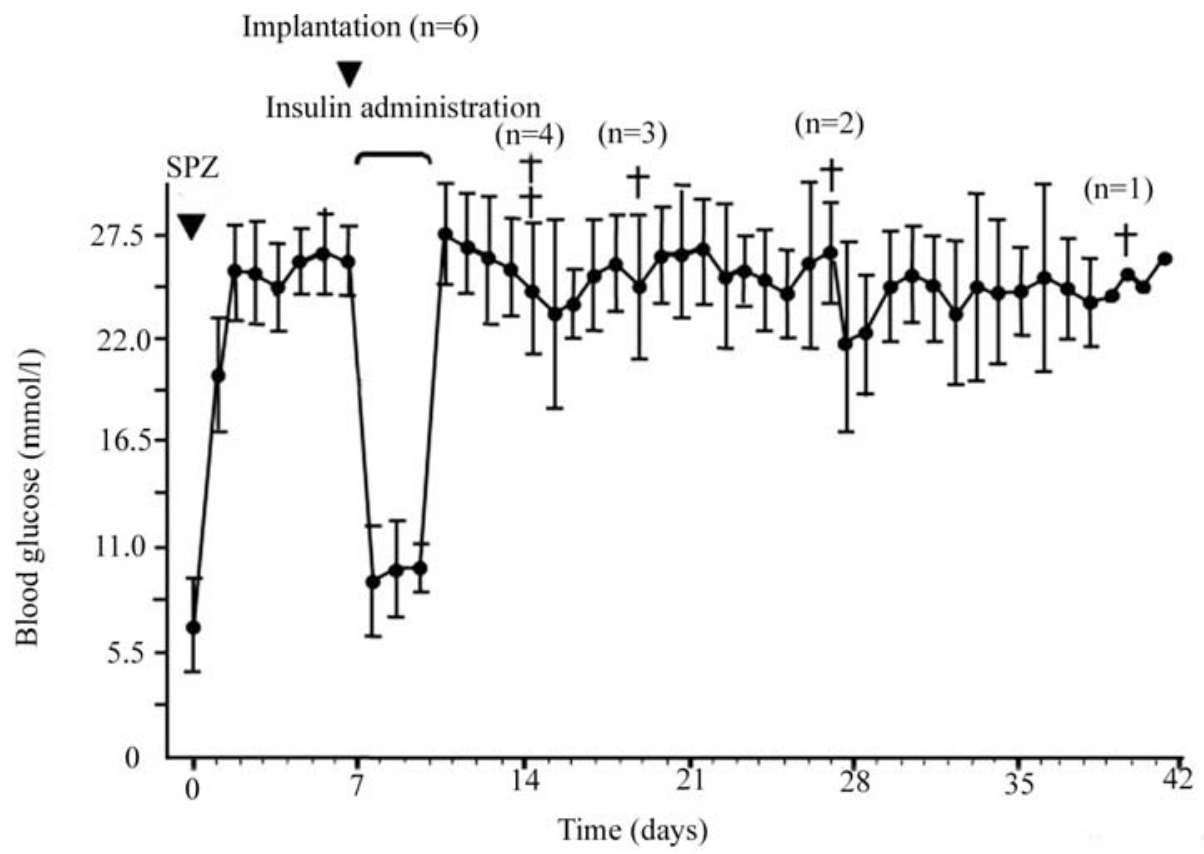

Figure 6. Time course of daily glucose levels in diabetic rats implanted with a tubular device without islets. The values are expressed as mean \pm SD.

control. It is noteworthy that starting from the 15 th day, the administered insulin dose, necessary to maintain glucose levels $<11 \mathrm{mmol} / \mathrm{l}$, significantly $(\mathrm{p}<0.05, \mathrm{p}<0.01$ from the 17 th day, $\mathrm{p}<0.001$ from the 30th day) decreased with a progressive trend for all the observation period, suggesting a long lasting viability of the islets contained in the implanted bioreactors. As a result of this in vivo experiment, we obtained an insulinic requirement improvement. However, diabetes has not been corrected and, as a consequence, diabetic rats were implanted with a double device number (6). Daily glucose and weekly insulin levels of implanted diabetic rats were measured (Fig. 5). After three days insulin therapy, a significant $(\mathrm{p}<0.05, \mathrm{p}<0.01)$ reduction of blood glucose levels, with respect to before implantation, was observed, reaching values $<11.0 \mathrm{mmol} / \mathrm{l}$. After removal of the implant, glucose levels returned to the initial high values. At the same time, plasma insulin levels, strongly reduced after diabetes induction ( $<<0.05$ vs. pre-SPZ), were restored after implantation, and significantly $(\mathrm{p}<0.05$ vs. 49th day) decreased two days after implantation removal. In diabetic rats implanted with a PVA/PEG tubular device without islets, as expected, the glucose levels remained high, similarly to the pre-implantation period. Moreover, the survival of animals was strongly reduced, as highlighted in SPZ diabetic untreated rats (Fig. 6). Fig. 7 shows the time course of daily glucose levels in diabetic rats implanted with islets adherent to AM without tubular device. It should be noted that 


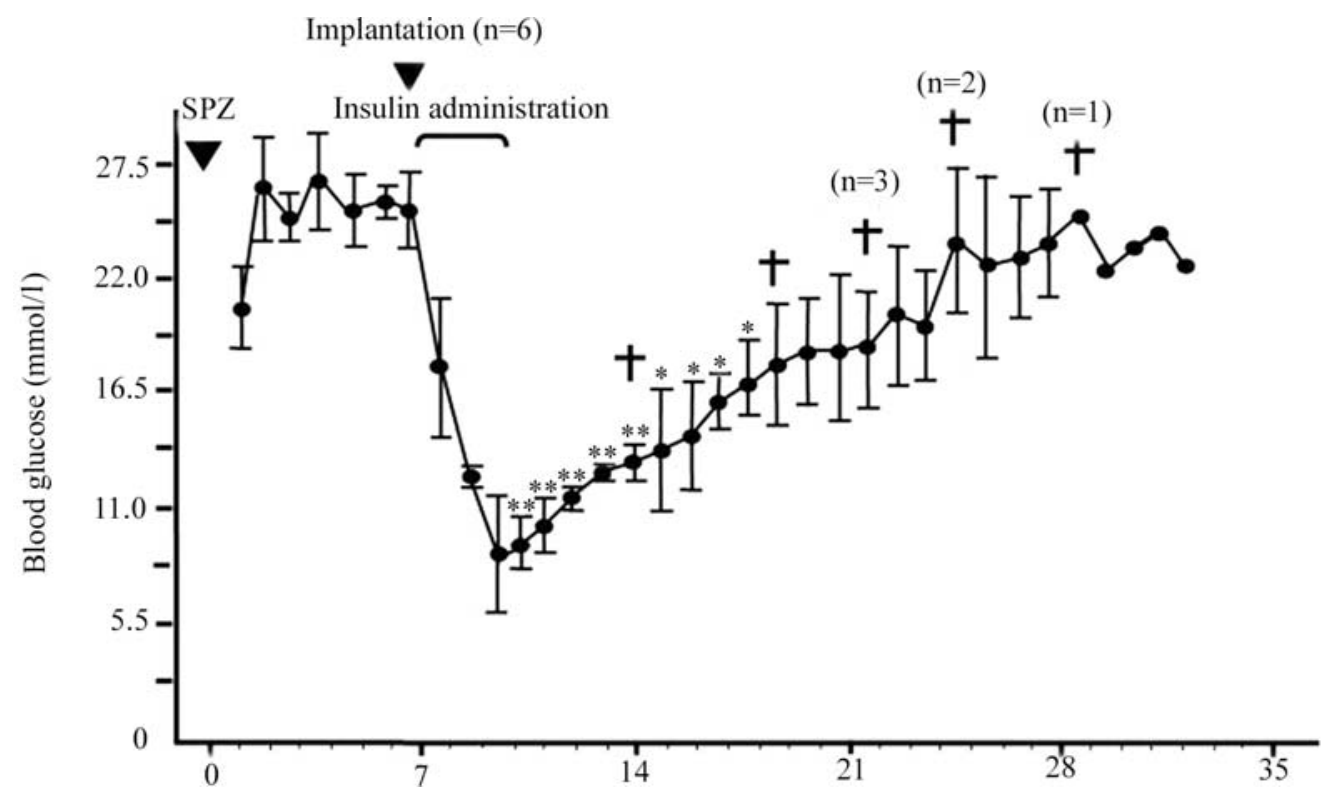

Figure 7. Time course of daily glucose levels in diabetic rats implanted with islets adherent to AM without tubular device. The values are expressed as mean $\pm \mathrm{SD} .{ }^{*} \mathrm{p}<0.05$ and ${ }^{* *} \mathrm{p}<0.01$ vs. implantation day.

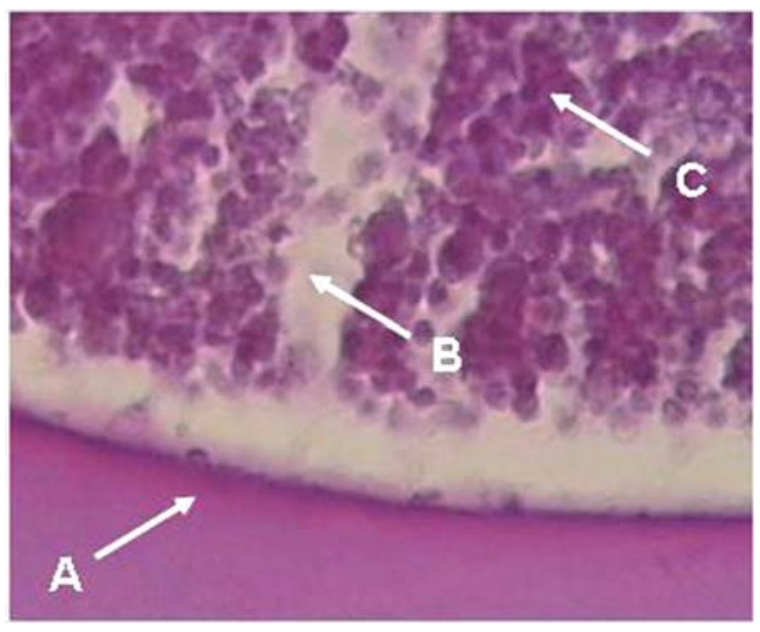

Figure 8. Light microscope section of a bioreactor recovered from transplanted rats stained by the Aldehyde-Fuchsin method. A, PVA membrane; B, AM; $\mathrm{C}$, islets (original magnification $\mathrm{x} 200$ ).

a significant ( $p<0.01, p<0.05$ vs. pre-implantation levels), but transient, reduction of glucose levels occured until the 19th day. Moreover, the survival rate of animals was strongly reduced after implantation.

Histological analysis. Sections of pancreatic devices, recovered from implanted rats, were stained with Aldehyde-Fuchsin method. As can be observed in Fig. 8, islets contained granulated cells comparable to the usual hormone secreting islet cells. Moreover, immunofluorescence staining showed that islets were positive either to insulin or glucagon (Fig. 9).

\section{Discussion}

Transplantation of pancreatic islets enclosed in a semipermeable membrane has been proposed as a safe and
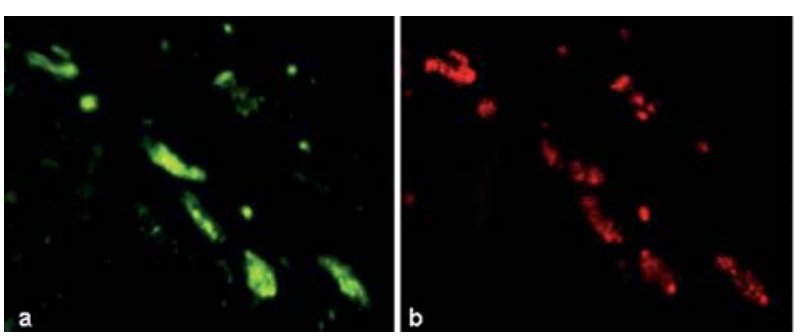

Figure 9. Immunofluorescence staining of section incubated with monoclonal anti-insulin (a) and anti-glucagon (b) immunoglobulins (original magnification, $\mathrm{x} 100)$.

effective method for treating type 1 diabetes mellitus without the need for immunosuppressive therapy. Various types of bioartificial pancreas have been proposed and developed, including islet micro- or macroencapsulation $(5,6)$. In the present study, a device, constituted of rat pancreatic islets seeded on the pancreatic acellular matrix (AM) and incapsulated into a PVA/PEG semi-permeable membrane, was developed.

The extracellular matrix (ECM) is a dynamic and complex structure and regulates not only three-dimensional tissue organization, but also cellular morphogenesis, proliferation, migration and metabolic functions $(26,40)$. It has been demonstrated that ECM derived from rat bladder carcinoma cells (804G-ECM) has positive effects on in vitro rat primary $\beta$-cell function and survival (20,41-43). Indeed, after adhesion on matrix, rat pancreatic $\beta$-cells spread in response to glucose and secrete more insulin compared to cells cultured on polyL-lysine (41). This study provides evidence of activation of signalling pathways and gene expression by ECM leading to improved pancreatic $\beta$-cell survival before transplantation (20). Starting from these observations, we decided to investigate the possible use of pancreatic and/or liver AMs as biological 
scaffolds for pancreatic islets in order to prolong cell survival, maintenance, and function. Pancreatic AM was a proper biological culture substrate. Our data showed the preservation of glucose-stimulated insulin secretion in islets cultured on pancreatic matrix during six weeks in vitro incubation. On the contrary, islet function was impaired when cells were cultured without matrix or on liver AM. These data support the hypothesis that the organ-specific AM interacts with islets favouring their physiological response to glucose during longterm incubation. Moreover, it is possible that the interaction and subsequent adhesion to the pancreatic matrix prevents islet aggregation in clusters, that have been reported to cause the loss of implant viability (44). However, we cannot exclude that in our experiments, islet proliferation or differentiation of some contaminant ductal cells in mature islets are induced by pancreatic matrix during in vitro culture or in vivo implantation.

We used tubular poly(vinyl alcohol)/poly(ethylene glycol) (PVA/PEG) membranes to entrap and isolate islets/pancreatic matrix cultures. Freeze-thawing technique permits to obtain PVA device cryogels with very high micro- and macroporosities, providing favoured conditions for substrate transfer (45) and PVA cryogels have been used for biomedical and drug delivery applications (46). However, it has been demonstrated that these scaffolds possess weak mechanical strength and, as a consequence, several enhancers, including polyethylene terephthalate meshes, glutaraldehyde and alginate (47-50) have been used. Here, to improve mechanical properties, PEG was added to the PVA membrane formation system. Indeed, mechanical property increase can be obtained using PEG at a higher molecular weight, such as PEG 600 and PEG 1000, and with a higher ratio PEG/PVA $(12,45)$. PEG allowed us to obtain a device with an asymmetric structure and an increased matrix reinforcement $(7,13)$. Moreover, PVA/PEG membranes have been known to be non-toxic for islets and possess a good permeability for glucose, insulin and albumin, preventing immunoglobulin $\mathrm{G}$ passage (8).

We have demonstrated that our pancreatic devices containing islets adherent to pancreatic AM allowed, during prolonged in vitro incubation, islet response to glucose acute stimulations and insulin delivery throughout the bioreactor membrane. Moreover, in SPZ diabetic rats, implantation led to a reduction of daily insulin needed to maintain the euglycaemic state. The observed reduced insulin requirement remained stable during the last two weeks, suggesting an insulin secretory activity of the islets contained in the device and a functional 'steady state' of the implantation. This hypothesis is supported by the observation that the in vivo implantation of a double number of devices determined a strongly significant reduction of blood glucose levels, compared to untreated rats. The blood glucose levels remained stably $<11.0 \mathrm{mmol} / \mathrm{l}$ during six weeks and returned to the initial values after implant removal. Moreover, insulin levels, strongly reduced after SPZ treatment, were restored after the implantation becoming undetectable after the removal of the implant.

However, a complete normalization of blood glucose levels was not achieved. This could be due to a non-optimal islets and/or device number, to the lack of intra-islet vascularisation and innervation or to the device location. Device size led us to consider only the subcutaneous implantation and the islets' exposure to peripheral blood circulation is clearly less effective with respect to the intra portal islet implant. Nevertheless, the long lasting reduction of glucose levels and the restoration of adequate insulin plasma levels in implanted rats indicate the persistence of viable and secreting ß-cells. Indeed, the microscope evaluation of islet and matrix morphology in the recovered devices support the integrity of both $\alpha$ and $\beta$-cells.

Taken together, our results show that i) pancreatic acellular matrix is a valuable scaffold able to maintain long-term islet viability and function both in vitro and in vivo and ii) PVA/PEG semi-permeable membrane successfully obtains devices that restore, at least in part, insulin secretion. Further in vivo studies will be needed to establish the islet number required to achieve the euglycaemic state.

\section{Acknowledgements}

The excellent technical skills and expertise of M. Basso is greatly appreciated. This work was supported by the following grants, (i) from the Italian Ministry of Education, Universities and Research (MIUR): RBNE01KCX4_008 MIUR-FIRB to P.P. Parnigotto; (ii) from the Regione Veneto (Italy) 181/04 to E. De Carlo.

\section{References}

1. Daneman D: Islet cell transplantation and other new technologies for treating type 1 diabetes: a paediatric view. Horm Res 57: 54-59, 2002.

2. Ryan EA, Lakey JR, Rajotte RV, Korbutt GS, et al: Clinical outcomes and insulin secretion after islet transplantation with the Edmonton protocol. Diabetes 50: 710-719, 2001.

3. Pipeleers D, Keymeulen B, Chatenoud L, et al: A view on beta cell transplantation in diabetes. Ann NY Acad Sci 958: 69-76, 2002.

4. Lim F and Sun AM: Microincapsulated islets as bioartificial endocrine pancreas. Science 210: 908-910, 1980.

5. Suzuki K, Bonner-Weir S, Trivedi N, Yoon KH, Hollister-Lock J, Colton CK and Weir GC: Function and survival of macroencapsulated syngeneic islets transplanted into streptozotocindiabetic mice. Transplantation 66: 21-28, 1998.

6. De Vos P, Hamel AF and Tatarkiewicz K: Considerations for successful transplantation of encapsulated pancreatic islets. Diabetologia 45: 159-173, 2002.

7. Young TH, Chuang WY, Yao NK and Chen LW: Use of a diffusion model for assessing the performance of poly(vinyl alcohol) bioartificial pancreases. J Biomed Mater Res 40: 385-391, 1998.

8. Young TH, Chuang WY, Hsieh MY, Chen LW and Hsu JP: Assessment and modeling of poly(vinyl alcohol) bioartificial pancreas in vivo. Biomaterials 23: 3495-3501, 2002.

9. Omer A, Duvivier-Kali VF, Trivedi N, Wilmot K, Bonner-Weir S and Weir GC: Survival and maturation of microincapsulated porcine neonatal pancreatic cell clusters transplanted into immunocompetent diabetic mice. Diabetes 52: 69-75, 2003.

10. Watase M, Nishinari K and Nambu M: Rheological properties of an anomalous poly(vinyl alcohol) gel. Polym Commun 24: $52-54,1983$.

11. DeMerlis CC and Schoneker DR: Review of the oral toxicity of polyvinyl alcohol (PVA). Food Chem Toxicol 41: 319-326, 2003.

12. Lozinsky VI, Zubov AL and Makhlis TA: Entrapment of Zymomonas mobilis cells into PVA-cryogel carrier in the presence of polyol cryoprotectants. In: Immobilied Cells: Basics and Applications. Wijffels RH, Buitelaar RM, Bucke C and Tramper J (eds). Elsevier Science BV, Amsterdam, pp112-117, 1996.

13. Graham NB: Poly(Ethylene glycol) gels and drug delivery. In: Polyethylene Glycol: Chemistry and Biological Applications (Acs Symposium Series). Harris JM and Zalipsky S (eds). Plenum Publications Corp., New York, pp263-281, 2004.

14. Kuchenbauer F, Hopfner U, Stalla J, Arzt E, Stalla GK and Páez-Pereda M: Extracellular matrix components regulate ACTH production and proliferation in corticotroph tumor cells. Mol Cell Endocrinol 175: 141-148, 2001. 
15. Rodgers RJ and Irving Rodgers HF: Extracellular matrix of the bovine ovarian membrana granulosa. Mol Cell Endocrinol 191: 57-64, 2002.

16. Nagata NA, Inoue K and Tabata Y: Co-culture of extracellular matrix suppresses the cell death of rat pancreatic islets. J Biomater Sci Polym Ed 13: 579-590, 2002.

17. Lucas-Clerc C, Massart C, Campion JP, Launois B and Nicol M: Long-term culture of human pancreatic islets in an extracellular matrix: morphological and metabolic effects. Mol Cell Endocrinol 94: 9-20, 1993.

18. Lefebvre VH, Otonkoski T, Ustinov J, Huotari MA, Pipeleers DG and Bouwens L: Culture of adult human islet preparations with hepatocyte growth factor and $804 \mathrm{G}$ matrix is mitogenic for duct cells but not for ß-cells. Diabetes 47: 134-137, 1998.

19. Ris F, Hammar E, Bosco D, et al: Impact of integrin-matrix matching and inhibition of apoptosis on the survival of purified human beta-cells in vitro. Diabetologia 45: 841-850, 2002.

20. Hammar E, Parnaud G, Bosco D, et al: Extracellular matrix protects pancreatic $\beta$-cells against apoptosis role of short- and long-term signaling pathways. Diabetes 53: 2034-2041, 2004.

21. Edamura K, Nasu K, Iwami Y, Ogawa H, Sasaki N and Ohgawara H: Effect of adhesion or collagen molecules on cell attachment, insulin secretion, and glucose responsiveness in the cultured adult porcine endocrine pancreas: a preliminary study. Cell Transplant 12: 439-446, 2003.

22. Beattie GM, Lappi DA, Baird A and Hayek A: Functional impact of attachment and purification in the short term culture of human pancreatic islets. J Clin Endocrinol Metab 73: 93-98, 1991.

23. Kaiser N, Corcos AP, Sarel I and Cerasi E: Monolayer culture of adult rat pancreatic islets on extracellular matrix: modulation of $ß$-cell function by chronic exposure to high glucose. Endocrinology 129: 2067-2076, 1991.

24. Perfetti R, Henderson TE, Wang Y, Montrose-Rafizadeh C and Egan JM: Insulin release and insulin mRNA levels in rat islets of Langerhans cultured on extracellular matrix. Pancreas 13: 47-54, 1996.

25. Nagata N, Gu Y, Hori H, et al: Evaluation of insulin secretion of isolated rat islets cultured in extracellular matrix. Cell Transplant 10: 447-451, 2001.

26. Wang RN and Rosenberg L: Maintenance of beta-cell function and survival following islet isolation requires re-establishment of the islet-matrix relationship. J Endocrinol 163: 181-190, 1999.

27. Burra P, Tomat S, Conconi MT, et al: Acellular liver matrix improves the survival and functions of isolated rat hepatocytes cultured in vitro. Int J Mol Med 14: 511-515, 2004.

28. Conconi MT, De Coppi P, Di Liddo R, Vigolo S, Zanon GF Parnigotto PP and Nussdorfer GG: Tracheal matrices, obtained by a detergent-enzymatic method, support in vitro the adhesion of chondrocytes and tracheal epithelial cells. Transpl Int 18: 727-734, 2005.

29. Dettin M, Conconi MT, Gambaretto R, Bagno A, Di Bello C, Menti AM, Grandi C and Parnigotto PP: Effect of synthetic peptides on osteoblast adhesion. Biomaterials 26: 4507-4515, 2005.

30. Parnigotto PP, Marzaro M, Artusi T, Perrino G and Conconi MT: Short bowel syndrome: experimental approach to increase intestinal surface in rats by gastric homologous acellular matrix. J Pediatr Surg 35: 1304-1308, 2000.

31. Parnigotto PP, Gamba PG, Conconi MT and Midrio P: Experimental defect in rabbit urethra repaired with acellular aortic matrix. Urol Res 28: 46-51, 2000.

32. Marzaro M, Conconi MT, Perin L, et al: Autologous satellite cell seeding improves in vivo biocompatibility of homologous muscle acellular matrix implants. Int J Mol Med 10: 177-182, 2002.
33. Conconi MT, De Coppi P, Bellini S, et al: Homologous muscle acellular matrix seeded with autologous myoblasts as a tissueengineering approach to abdominal wall-defect repair. Biomaterials 26: 2567-2574, 2005.

34. Marzaro M, Vigolo S, Oselladore B, et al: In vitro and in vivo proposal of an artificial esophagus. J Biomed Mater Res A 77: 795-801, 2006

35. Conconi MT, Bellini S, Teoli D, et al: In vitro and in vivo evaluation of acellular diaphragmatic matrices seeded with muscle precursors cells and coated with VEGF silica gels to repair muscle defect of the diaphragm. J Biomed Mater Res 89: 304-316, 2008.

36. Lacy PE and Kostianovsky M: Method for the isolation of intact islets of Langerhans from the rat pancreas. Diabetes 16: 35-39, 1967.

37. De Carlo E, Milanesi A, Martini C, Maffei P, Sicolo N and Scandellari C: Endothelin-1 and endothelin-3 stimulate insulin release by isolated rat pancreatic islets. $\mathrm{J}$ Endocrinol Invest 23: 240-245, 2000.

38. Meezan E, Hjelle JT and Brendel K: A simple, versatile, nondisruptive method for the isolation of morphologically and chemically pure basement membranes from several tissues. Life Sci 17: 1721-1732, 1975 .

39. Gomori G: Aldehyde-fuchsin: a new stain for elastic tissue. Am J Clin Pathol 20: 665-666, 1950 .

40. Aharoni D, Meiri I, Atzmon R, Vlodavsky I and Amsterdam A: Differential effect of components of the extracellular matrix on differentiation and apoptosis. Curr Biol 7: 43-51, 1997.

41. Bosco D, Meda P, Halban PA and Rouiller DG: Importance of cell-matrix interactions in rat islet $\beta$-cell secretion in vitro: role of alpha6beta1 integrin. Diabetes 49: 233-243, 2000.

42. Parnaud G, Hammar E, Rouiller DG, Armanet M, Halban PA and Bosco D: Blockade of $B 1$ integrin-laminin-5 interaction affects spreading and insulin secretion of rat $\beta$-cells attached on extracellular matrix. Diabetes 55: 1413-1420, 2006.

43. Ribaux P, Ehses JA, Lin-Marq N, et al: Induction of CXCL1 by extracellular matrix and autocrine enhancement by interleukin-1 in rat pancreatic ß-cells. Endocrinology 148: 5582-5590, 2007.

44. De Vos P and Marchetti P: Encapsulation of pancreatic islets for transplantation in diabetes: the untouchable islets. Trends $\mathrm{Mol}$ Med 8: 363-366, 2002.

45. Lozinsky VI and Plieva FM: Poly(vinyl alcohol) cryogels employed as matrices for cell immobilization. 3. Overview of recent research and developments. Enzyme Microb Technol 23: 227-242, 1998

46. Hassan CM, Stewart JE and Peppas NA: Diffusional characteristics of freeze/thawed poly(vinyl alcohol) hydrogels: applications to protein controlled release from multilaminate devices. Eur J Pharm Biopharm 49: 161-165, 2000.

47. Aung $\mathrm{T}$, Kogire $\mathrm{M}$, Inoue $\mathrm{K}$, et al: Insulin release from a bioartificial pancreas using a mesh reinforced polyvinyl alcohol hydrogel tube. An in vitro study. ASAIO J 39: 93-96, 1993

48. Aung T, Inoue K, Kogire M, et al: Comparison of various gels for immobilization of islets in bioartificial pancreas using a meshreinforced polyvinyl alcohol hydrogel tube. Transplantation Proc 27: 619-621, 1995.

49. Hayashi $\mathrm{H}$, Inoue $\mathrm{K}$, Aung $\mathrm{T}$, et al: Long survival of a xenografted bioartificial pancreas with a mesh-reinforced polyvinyl alcohol hydrogel bag employing a B-cell line (MIN6). Transplantation Proc 28: 1428-1429, 1996.

50. Storrs R, Dorian R, King SR, Lakey J and Rilo H: Preclinical development of the islet sheet. Ann NY Acad Sci 944: 252-266, 2001. 